\title{
The nature and use of bereavement support services in a hospice setting
}

\author{
A Roberts and S McGilloway Department of Psychology, National University of Ireland at Maynooth, \\ County Kildare
}

This study formed part of a larger project designed to evaluate a hospice-based bereavement support service in Ireland. It involved a detailed assessment of the views of service attenders and non-attenders. A postal survey was administered to all bereaved clients who were invited to one or more bereavement support services ( $n=517)$. Respondents $(n=243 ; 47 \%)$ completed: 1$)$ a Bereavement Services Questionnaire; 2 ) a measure of grief reaction (TRIG) and 3 ) a measure of religiosity (SCSORF). A total of 243 people $(47 \%)$ returned completed questionnaires, most of whom were satisfied with the service, (although not all had attended all elements of the bereavement service). However, a number of improvements were emphasised. Several statistically significant differences $(P<0.05)$ also emerged between service attenders and nonattenders with respect to grief reaction and other key factors (e.g., the age and relationship to the deceased). The findings emphasise the needs and views of both attenders and non-attenders and provide important lessons for the implementation and development of hospice-based bereavement support services. Palliative Medicine (2008); 22: $612-625$

Key words: bereavement services; hospice care; non-attenders; palliative care; service-users

\section{Introduction}

There is growing recognition of the importance of providing bereavement support services in palliative care settings, but few studies have evaluated the effectiveness of these services. ${ }^{1-4}$ The National Institute of Clinical Excellence (2004) recommends that each provider organisation should offer, or have access to, three levels of bereavement support. However, there is no guidance on the nature or delivery of these services. ${ }^{4}$ Importantly, key commentators in the field consider it 'unethical' to introduce services for the bereaved that are not well founded and evaluated. ${ }^{5}$ Furthermore, the extent and nature of bereavement support tend to vary widely and may range from telephone calls and the provision of written information for bereaved relatives to one-to-one support, social activities and therapeutic and self-help groups. ${ }^{6}$ The few studies that have evaluated hospice-based bereavement support services tend to focus on only one aspect of the service ${ }^{7-9}$ or on the health outcomes mainly of one-to-one forms of support. ${ }^{10-12}$ More research in this area is needed to inform service planning and delivery, and the current study aimed to address this gap in our knowledge by con-

Correspondence to: Amanda Roberts, Department of Psychology, The John Hume Building, National University of Ireland at Maynooth, County Kildare, Ireland.

Email: amandaroberts77@yahoo.com ducting a comprehensive assessment and evaluation of a hospice-based bereavement support service in Ireland. This article reports the first part of the study, the main aims of which were to: 1) to describe the support services currently available at a large hospice in Dublin; 2) assess the reasons why people did, or did not attend, the different services and 3) to ascertain the views and needs of service attenders and non-attenders on the services that are currently available.

The hospice that is the focus of this study is one of the largest of eight hospices in Ireland. It provides inpatient (19 beds), day care and home care services for a catchment population in North Dublin of almost half a million. ${ }^{13}$ It provides respite and palliative care to people mainly in the advanced stages of cancer or motor neurone disease and serves approximately 700 new patients a year, almost twothirds of whom are aged over 65 . The bereavement support service comprises four main elements including: 1) a bereavement follow-up contact made to a family member by hospice staff shortly after the death;2) a Monthly Memorial Ceremony (MMC); 3) a Bereavement Information Evening (BIE), which entails a presentation by the hospice social worker on the bereavement process and the hospice bereavement services and 4) a Volunteer Bereavement Support Service (VBSS), which comprises a listening service provided by trained volunteers under the supervision of the hospice social work team. 


\section{Method}

The study involved a cross-sectional postal survey $(n=517)$ of: 1$)$ all bereaved clients who were invited to attend the MMC and/or the BIE during the previous 12 months $(n=370)$ and 2$)$ all those clients who attended the VBSS during the previous 2 years $(n=147)$. The study was approved by the hospice Ethics Committee.

\section{Measures}

Participants who were invited to attend one or more of the bereavement services (MMC or BIE) over a 12-month period or who accessed the VBSS over a 2-year period were sent a Bereavement Service Questionnaire (BSQ) (appendix). This was designed for purposes of the study to elicit information on background characteristics and clients' views. The former included age and sex of both clients and their deceased relatives, as well as the respondent's relationship to the deceased, time since death, social support and religiosity. No information on ethnicity or language was collected as an analysis of routinely available information at the hospice indicated that virtually all of the patients under its care are native Irish (almost 99\% (817/827) in 2007).

Two additional measures were subsumed within the BSQ to assess grief symptoms at the time of the study and religiosity (see below). Three versions of the BSQ had to be devised because not all the bereaved relatives and friends were invited to attend all three of the services; consequently, the questions had to be tailored accordingly. 1) The $M M C B S Q$ was administered to families who were invited to attend the monthly memorial ceremony (i.e., families of patients cared for in the in-patient unit; these families were also invited to attend a BIE). 2) The BIE BSQ was administered to families who were invited only to the BIE (i.e., families of home care patients). 3) Those who attended the VBSS over a 2-year period were asked to complete the VBSS BSQ. Each of the questionnaires included a limited number of items about the other two services because some families were invited or had access to more than one of the services. Both open and closed questions were used to obtain both quantitative and semi-qualitative data (see Appendix).

The Texas Revised Inventory of Grief $(T R I G)^{14}$ is a brief, widely used and psychometrically robust measure of the intensity and nature of an individual's grief response. The scale comprises 26 items with three subscales that measure past behaviour, present feelings and a number of unscaled items relating to facts about the death. Only parts one and two were used in the current study to explore any differences in grief response between service attenders and non-attenders. The Santa Clara Strength of Religious Faith (SCSORF) ${ }^{15}$ is a 10-item instrument that assesses strength of religious faith irre- spective of religious denomination or affiliation, with higher scores reflecting stronger levels of 'religious faith' ${ }^{15}$ The SCSORF was only administered to those who were invited to attend the monthly liturgical ceremony to ascertain whether attenders and non-attenders of this service differed in their overall levels of religiosity.

\section{Results}

Overall, almost half $(47 \%, 243 / 517)$ of the sample returned completed questionnaires (i.e., MMC BSQ: 48\%, [89/183]; BIE BSQ: 41\% [78/187] and VBSS BSQ: 52\% [76/147]) although the total number responding to questions on each service element varied because not everyone was invited to, or chose to avail of, each of the three services (hence, the variation in the denominators below). The results for each service element are presented below; the total number of respondents who used/did not use each of the three services is presented in Table 1. The information common to all three versions of the BSQ included attendance rates, reasons for attending/not attending and aspects of the service that were found to be helpful. However, it was possible only to undertake an attender versus non-attender comparison for the BIE BSQ data because the two MMC groups were far too unequal to permit a meaningful comparison, whereas no appropriate comparison group of VBSS non-attenders was available.

\section{Bereavement follow-up contact}

Eighty-one per cent (136/167) of those respondents who were asked about bereavement follow-up (i.e., MMC and BIE BSQ) had received some form of contact (2/167 did not answer this question), almost half of which were telephone-based and conducted by nurses. Most of those who did not receive a follow-up call (22/29) would have liked to have such contact following the death of their relative or friend. Approximately, two-thirds of respondents $(67 \%, 112 / 167)$ found these contacts helpful (although 41 respondents did not answer this question).

\section{Monthly memorial ceremony (MMC)}

The majority of respondents $(87 \%, 77 / 89)$ who were invited to the Monthly Memorial Ceremony (i.e., MMC BSQ) attended. More than one quarter $(28 \%, 25 / 89)$ of respondents would have liked the option of attending a non-religious service (although 23 respondents did not answer this question). Participants who completed the VBSS BSQ who reported that they had also attended a MMC $(n=42)$ were asked for their reason(s) for attendance. One in four of these respondents (16/42) hoped that it would bring them comfort and help them cope 
Table 1 Summary table of respondents' attendance/non-attendance at each of the three bereavement service elements ${ }^{a}$

\begin{tabular}{|c|c|c|c|c|c|c|}
\hline \multirow[t]{2}{*}{ Attendance } & \multicolumn{2}{|c|}{ MMC BSO $(n=89)$} & \multicolumn{2}{|c|}{ BIE BSO $(n=78)^{\mathrm{b}}$} & \multicolumn{2}{|c|}{ VBSS BSO $(n=76)^{\mathrm{c}}$} \\
\hline & Attended & Not attended & Attended & Not attended & Attended & Not attended \\
\hline MMC & 77 & 12 & - & - & 42 & 34 \\
\hline BIE & 17 & 65 & 26 & 47 & 43 & 33 \\
\hline VBSS & \multicolumn{4}{|c|}{8 attended/159 not attended ${ }^{d}$} & 76 & \\
\hline
\end{tabular}

MMC, Monthly Memorial Ceremony; BIE, Bereavement Information Evening; VBSS, Volunteer Bereavement Support Service; BSQ, Bereavement Service Questionnaire.

aThree questionnaires were designed for purposes of this study. 1) The MMC BSO was sent to families who were invited to attend a monthly ceremony (families of in-patient unit patients). 2) The BIE BSO was sent to families who were only invited to the information evening (families of home care patients). 3) The VBSS BSQ was sent to individuals who accessed the VBSS over a 2-year period. Each of the questionnaires included a limited number of items about the other two services.

${ }^{\mathrm{b}}$ Five respondents were unsure whether or not they had attended the BIE.

'The VBSS BSO was only administered to those who self-referred to the VBSS over a 2-year period as individuals are not invited to use this service.

${ }^{\mathrm{d}}$ Respondents who completed the MMC BSO or the BIE BSO and reported that they either attended or did not attend the VBSS.

with their loss, and approximately the same proportion (10/42) attended to honour and remember their deceased relative or friend. Five respondents reported that they wished to be with others who had suffered a similar loss. One in ten attended as a way of saying 'thank-you' to the hospice for the support they offered them throughout their relative/friend's illness. Other less common reasons (7/42) for attending included a desire to feel close to the deceased and an opportunity to bring the family together.

Most of the 12 respondents (13\%, 12/89 - MMC BSQ) who did not attend the ceremony indicated more than one reason for not doing so. The most commonly reported reasons included: the feeling that it would be too painful and/or unhelpful at the time (8/12); a desire not to return to the hospice (7/12); the service occurring too soon after the death (5/12); the religious nature of the ceremony $(5 / 12)$ and inconvenience (4/12). The majority of those who attended the ceremonies were satisfied with the service $(86 \%, 66 / 77)$ (see Figure 1) although approximately one in ten (7/77) stated that the ceremonies could be improved (seven people did not answer this question). For example, five felt that the ceremonies were overcrowded and that the staff who were present appeared to be more involved in serving tea after the ceremony rather than using the time for follow-up; thereby missing the opportunity to link in with families. Unfortunately, a meaningful analysis of attenders and non-attenders with respect to grief symptoms or religiosity could not be conducted because of the large disparity in group sizes (i.e., attenders $=77$; non-attenders $=12$ ).

\section{The bereavement information evening (BIE)}

With regard to those who had received an invitation to the Bereavement Information Evening (i.e., BIE BSQ), one- third (26/78) reported that they had attended this event. Most attenders $(84 \%, 22 / 26)$ stated that they were satisfied with the support provided (Figure 1).

Participants who completed the VBSS BSQ and who reported that they had also attended a BIE (43/76) were asked why they chose to attend the service; more than one-third $(35 \%, 15 / 43)$ reported that they had done so to seek help to cope with their loss. A further one-quarter (11/43) wished to obtain information on bereavement and the type of services provided by the hospice. One in five indicated a need to ascertain whether or not their grieving experience was 'normal'. The same proportion expressed a desire to meet with others who had suffered a similar bereavement. Other reasons for attending included the opportunity to introduce family members to the hospice bereavement services (2/43) and an obligation to attend because individuals had been invited (3/43). However, seven respondents recommended some improvements. For example, two found the BIE to be

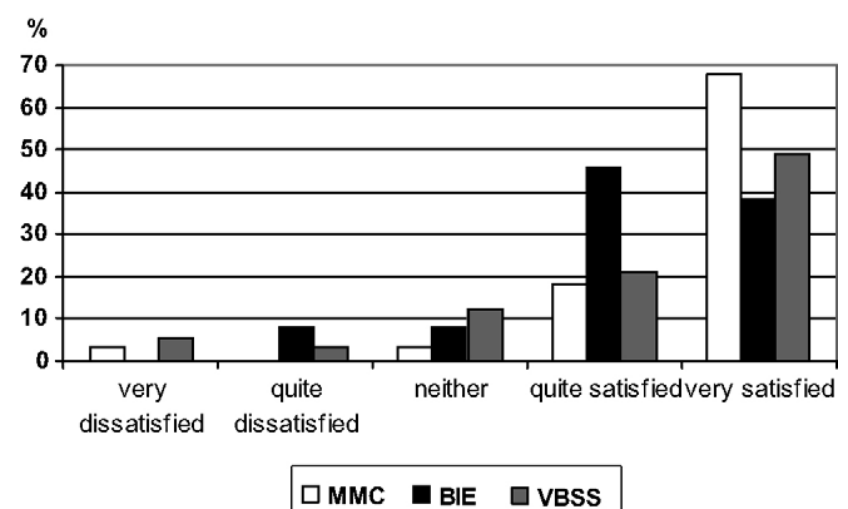

Figure 1 Overall levels of satisfaction with the three bereavement service elements. 
Table 2 Reason(s) why respondents chose not to attend the BIE (MMC BSO and BIE BSQ; $n=112$ )

\begin{tabular}{ll}
\hline $\begin{array}{l}\text { Reason(s) why respondents chose not to } \\
\text { attend the BIE }\end{array}$ & $n(\%)$ \\
\hline Timing inconvenient $^{\mathrm{b}}$ & $40(38)$ \\
Too painful & $34(30)$ \\
No or insufficient notice & $22(20)$ \\
Felt they could cope on their own & $20(18)$ \\
Felt the BIE was too soon after the death & $16(14)$ \\
Could not return to the hospice & $13(12)$ \\
Felt the BIE was too long after the death & $3(3)$ \\
Other $^{\mathrm{c}}$ & $7(6)$ \\
\hline
\end{tabular}

MMC, Monthly Memorial Ceremony; BIE, Bereavement Information Evening; VBSS, Volunteer Bereavement Support Service; BSQ, Bereavement Service Questionnaire.

a Some respondents gave more than one reason for not attending.

bThese were all response options provided for the respondents (following the pilot study) to make the questionnaire completion as straightforward as possible.

'Other' includes: 'did not want to go out at night-time' and 'a feeling that attending the BIE would not bring the deceased relative back'.

too crowded and the topics covered to be too broad; they also suggested that more staff should be present, especially those nursing staff who had cared for their relative/friend.

Approximately, two-thirds of participants invited to the BIE $(67 \%, 112 / 167$ [MMC BSQ and BIE BSQ: $n=167])$ reported that they did not attend the service. Respondents gave a variety of reasons for not attending, the most common of which included: the inconvenient timing of the BIE (40/112); thoughts that it might be too painful to attend (34/112); no or insufficient notice of the BIE and a feeling of being able to cope on their own (20/112) (see Table 2).

A statistical comparison of respondents (i.e., MMC and BIE BSQ; $n=167)$ who attended $(n=43)$ the BIE and those who did not attend $(n=112)$ was conducted with respect to the TRIG and other background variables
(12/167 did not fully complete the TRIG). A series of $t$ tests was conducted on the continuous variables, whereas chi-squared tests were applied to categorical variables (see Tables 3 and 4). The results showed that those who attended the BIE, when compared with non-attenders, reported significantly higher levels of grief symptoms on the TRIG, both at the time of the death and at the time of the study (see Table 3). Attenders were more likely to be the principal carer for the deceased and have a closer relationship to them (e.g., parent, partner or child). They were also significantly less likely than non-attenders to agree that they had enough practical and emotional support at the time of the death. Additionally, the deceased relatives/ friends of the attenders were more likely to be younger than those of the non-attenders. (Table 4).

\section{The volunteer bereavement support service (VBSS)}

Those who accessed the VBSS during the previous 2 years were asked to complete a VBSS BSQ; over half $(52 \%$, 76/147) returned a completed questionnaire. Respondents indicated a number of reasons for attending the service, $58 \%$ of whom (44/76) attended to talk to someone outside their family. Approximately, 40\% (31/76) attended because they felt that they could not cope with their grief on their own, whereas one in five (15/76) reported attending only because their family/friends had persuaded them to do so. A further $10 \%$ stated that they had no one else to talk to. Other reasons for attending (4/76) the service included a search for confirmation by respondents that they were 'coping o $k$ ' and that they were grieving in an appropriate way (4 of the 76 respondents did not answer this question).

More than two-thirds of VBSS responders ( $70 \%, 53 / 76)$ were satisfied with the service (see Figure 1) although a number of suggested improvements to the service were emphasised. These included: 1) increasing the number and type of support services available (e.g., to encompass group sessions); 2) ensuring that all bereaved families are

Table 3 Comparison (t-tests) of BIE attenders and non-attenders on key (numerical) variables

\begin{tabular}{|c|c|c|c|c|c|c|}
\hline \multirow[t]{2}{*}{ Variable } & \multicolumn{2}{|r|}{ Attenders } & \multicolumn{2}{|r|}{ Non-attenders } & \multirow[t]{2}{*}{$P$ value $\left(\eta^{2}\right)$} & \multirow[t]{2}{*}{$t(\mathrm{df})$} \\
\hline & $n$ & Mean (SD) & $n$ & Mean (SD) & & \\
\hline Age of participant & 42 & $53(15)$ & 105 & $53(14)$ & 0.874 & $1.59(145)$ \\
\hline Age of deceased & 42 & $62(17)$ & 106 & $68(13)$ & $0.016 * \quad(0.04)$ & $2.46(146)$ \\
\hline TRIG (part 1)a & 42 & $26(8)$ & 100 & $22(8)$ & $0.007 * *(0.05)$ & $2.74(140)$ \\
\hline TRIG (part 2) ${ }^{\mathrm{b}}$ & 42 & $51(11)$ & 103 & $45(12)$ & $0.003 * *(0.06)$ & $3.05(143)$ \\
\hline SCSORFc & 15 & $30(8)$ & 55 & $28(9)$ & 0.509 & $6.64(68)$ \\
\hline Time since death & 43 & 11.3 months (2) & 112 & 10.9 months (2) & 0.357 & $0.92(153)$ \\
\hline
\end{tabular}

BIE, Bereavement Information Evening.

Range of scores: ${ }^{a}$ TRIG (part 1), 8-40; bTRIG (part 2), 13-65; ' $S C S O R F, 10-40$.

$*<0.05$.

$* *<0.01$. 
Table 4 Comparison of BIE attenders and non-attenders on key (categorical) variables

\begin{tabular}{|c|c|c|c|c|c|}
\hline & $\begin{array}{l}\text { Attenders } \\
n(\%)\end{array}$ & $\begin{array}{l}\text { Non-attenders } \\
n(\%)\end{array}$ & df & $\chi^{2}$ value & $P$ value \\
\hline \multicolumn{6}{|l|}{ Social support } \\
\hline Someone to talk to & & & 6 & 8.484 & 0.205 \\
\hline Availability of practical support & & & 6 & 14.320 & $0.026^{*}$ \\
\hline Availability of emotional support & & & 6 & 20.253 & $0.002 * *$ \\
\hline Relationship to the deceased & & & 12 & 22.435 & $0.033^{*}$ \\
\hline \multicolumn{6}{|l|}{ Gender } \\
\hline Male & $8(19)$ & $33(30)$ & & & \\
\hline Female & $35(81)$ & $79(70)$ & 2 & 2.129 & 0.345 \\
\hline \multicolumn{6}{|l|}{ Main carer } \\
\hline Yes & $35(88)$ & $68(67)$ & & & \\
\hline No & $5(12)$ & 34 (33) & 2 & 6.257 & $0.044 *$ \\
\hline \multicolumn{6}{|l|}{ Death expected/unexpected } \\
\hline Expected & $33(81)$ & $88(86)$ & & & \\
\hline Not expected & $8(19)$ & $13(13)$ & 4 & 2.438 & 0.656 \\
\hline \multicolumn{6}{|l|}{ Present/not present at death } \\
\hline Present at death & $37(88)$ & $87(82)$ & & & \\
\hline Not present & $5(12)$ & 19 (18) & 2 & 1.512 & 0.470 \\
\hline
\end{tabular}

appropriately informed of the service; 3) allowing clients the opportunity to change to a different volunteer if necessary and 4) addressing practical considerations such as using an alternative room within the hospice and using a more personal form of notification of the service.

The majority of participants who completed the MMC and BIE BSQ reported that they had not used the VBSS (159/167). A substantial proportion of this group (22\%, 35/159) were unaware of its existence although over half of them stated that they might have considered using the service, had they known about it. When asked specifically why they chose not to use the VBSS, 37\% (59/159) felt that they were coping with their loss in their own way or with the support and help of their family and friends. However, one in ten (16/159) respondents did not use the service because they felt it would be too painful or considered it too soon to talk about their loss. Some respondents stated that they did not use the VBSS because they were unaware of the service (12/159), whereas a small number reported that they did not have time to attend (7/159). Examples of less commonly reported reasons for not using the service included a sense on the part of respondents that it was inappropriate to talk to a stranger about the deceased and a reluctance to use hospice resources when they perceived others to be more in need (49/159 people did not reply to this question).

Those who attended both the VBSS and the other services reported that different aspects of each of the services were useful. For example, high proportions found the candle lighting ceremony $(92 \%)$ and the social work talk $(92 \%)$ at the monthly memorial ceremonies to be helpful. Those who attended the BIE also valued the opportunity to talk with others who had suffered the same loss and to learn that what they were going through was normal, as well as hearing information about the bereavement process and the supports available at the hospice. Those who used the VBSS reported that they had benefited from: being listened to and not feeling judged; the opportunity 'to unwind and pour your heart out'; feeling assured that they were neither "stupid" nor "mad"; being given the opportunity to discuss the person who had died with someone who was independent of family and friends; being able to talk about their relative/friend without feeling a nuisance; receiving confirmation that their feelings were normal and the opportunity to have a safe 'space' to grieve.

As indicated earlier, it was not possible to conduct a meaningful analysis (e.g., with respect to TRIG scores) to assess differences between attenders and non-attenders of the VBSS as family members self-refer to this service as opposed to being invited; therefore, an appropriate comparison group of non-attenders could not be identified. Nonetheless, some information about the VBSS nonattenders was obtained from those who were invited to attend the other bereavement services (MMC and BIE) (but who did not use the VBSS). The two sets of data are not strictly comparable because the non-attenders were asked only about the 12-month period after the death of the relative/friend (on the contrary to the 2-year period for the VBSS attenders).

\section{Discussion}

The findings presented in this article form part of a larger evaluation of the adult bereavement support services 
offered at an Irish hospice. This part of the study was undertaken to address a significant gap in our knowledge regarding the nature and use of, and satisfaction with, bereavement support services as they become increasingly available (and essential) within palliative care settings. Previous research in this area is limited and tends to focus on a single aspect of bereavement services such as one-to-one support. ${ }^{9-12}$ Notable exceptions include two recent studies conducted in the United Kingdom ${ }^{18}$ and the United States. ${ }^{19}$ The former involved the assessment of user and non-users in adult bereavement services across five hospices $(n=105)$ although only a small number of participants (18-27) were recruited from each hospice, and relatively few non-attenders $(n=23)$ were included. Similarly, the second Colorado Bereavement Services Project in the United States involved a follow-up survey of participants in six hospices $(n=1020)$ although there was very little emphasis on specific aspects of service delivery and more on bereavement outcomes. It is of further interest to note that a recent systematic review of bereavement intervention studies ${ }^{20}$ included 74 American studies, only one of which was conducted in a hospice setting; this study looked at hospice care as a system intervention for bereavement rather than as a hospice-based bereavement service per se.

The current study is the first of its kind to undertake a comprehensive examination of all elements of a hospicebased bereavement support service. The sub-study reported in this article is based on a large, crosssectional, postal survey and included both attenders and non-attenders to assess user satisfaction and to identify possible barriers to service provision. The response rate is typically low in studies involving the bereaved. ${ }^{10,21}$ Nonetheless, the current study had a response rate of $47 \%$, which compares favourably to a number of other studies utilising postal surveys, with response rates ranging from $41 \%$ to $47 \% .^{7-9}$ This was due to, in no small measure, the high levels of enthusiasm and support provided to the researcher by the hospice staff and management. As in previous work, ${ }^{18,19}$ a grief measure was administered to both attenders and non-attenders, although unlike work undertaken elsewhere, we were specifically interested in differences between attenders and non-attenders as opposed to any changes across time within each group separately. Twenty-two respondents agreed to participate in one-to-one interviews, and these data are not reported here (because of space constraints), the findings generally support the results of the postal survey.

The National Institute of Clinical Excellence (NICE) ${ }^{4}$ suggests that there should be three components (or levels) of bereavement support, ranging from providing information on the bereavement process to specialist mental health interventions. The guidance proposes that provider organisations should be equipped to offer the first compo- nent of bereavement support, such as bereavement and service information, and have strategies in place to access the other components. ${ }^{4}$ The hospice in the current study offers all of the levels of service provision proposed by NICE guidance. The BIE and MMC provide a formal means by which information about bereavement and support services are communicated to bereaved families (level 1). The VBSS allows families a structured opportunity to formally review and reflect on their loss (level 2), whereas those individuals requiring specialist intervention have access to on-site senior medical social workers and/or a weekly clinic run by a counselling psychologist (level 3).

Reassuringly, a majority of participants in this study were satisfied with the support services offered although respondents rated the Monthly Memorial Ceremonies and the BIE more favourably than the VBSS (see Figure 1). This is perhaps unsurprising in view of the nature and scale of the VBSS (and ongoing client contact) when compared with the other services. Nonetheless, a number of suggested improvements were emphasised across the four service components relating, in particular, to barriers to service provision, which ought to be addressed if the service is to operate at an optimal level and to meet the needs of as many of its clients as possible. Overall, the findings suggest that there may be some scope for improving some aspects of the services and especially the VBSS. These included, in particular, a perceived need to increase the number and type of support services available (e.g., to facilitate group sessions) and to ensure that all bereaved families are appropriately informed of the service. The second stage of this study, which is currently underway, specifically assesses the VBSS within the framework of a prospective (controlled) follow-up study of service attenders and non-attenders to assess changes in key outcomes over time and thereby to provide an indication of overall effectiveness.

Interestingly, participants who attended the BIE reported significantly higher levels of grief symptoms both at the time of death and at the time of the study than non-attenders. From a service provider perspective, this is reassuring as it suggests that the bereaved families who are most distressed appear to be using the service. Although we were unable to ascertain whether their grief symptoms were alleviated from attending the service, overall satisfaction levels were high. This is important not only in terms of providing bereaved relatives with some form of support but also because the BIE provides a 'gateway' to further support if required, such as the VBSS or specialist counselling provided by the social work team, as well as the weekly clinic run by a counselling psychologist. Previous research has found one-to-one support to be most beneficial for people who are suffering a more complicated bereavement. ${ }^{10,11}$

The current study has a number of limitations. Although the study included both attenders and non- 
attenders, those bereaved families who did not have a positive experience of the hospice may have been less likely to have participated in the study than those with more positive views. The number of attenders $(n=77)$ and nonattenders $(n=12)$ of the monthly ceremonies also differed to the extent that it was not possible to conduct a meaningful analysis between the two groups with respect to grief symptoms and religiosity, whereas the same was true with respect to the VBSS, in which case no comparison group of non-attenders was available. However, it is worth noting that other studies that have used the SCSORF reported similar mean scores with clinical populations of a similar age to those in the current study. ${ }^{16,17}$ Nonetheless, the high attendance rate could be considered a favourable outcome for this aspect of the service and the MMC; therefore, the service would appear to be meeting a high level of client need irrespective of the levels of religiosity amongst attenders. Finally, it would have been useful to assess any changes in grief symptoms as a result of using the services described in this article, but this part of the study was retrospective and cross-sectional in nature and was not designed, therefore, to take account of changes over time. However, this will be addressed, in part, by the second and more substantial stage of the study, which is designed to assess a range of pre- and post-intervention outcomes (e.g., grief symptoms, coping, social support, physical and mental health) in those who attend the one-to-one VBSS versus a (smaller) comparison group of non-attenders.

It should also be noted that this study included an assessment of the Annual Remembrance service at the local church and the annual 'Christmas Tree of Life' service attended by $36 \%$ and $12 \%$ of respondents, respectively. However, these were not included in this article because they are not core elements of the service. Service providers (both staff and volunteers) $(n=145)$ were also surveyed as part of this first stage, but these findings will be reported elsewhere.

Although bereavement support is widely regarded as an integral component of a palliative care service, there is little consensus about the nature of these services and how they should be delivered. ${ }^{11}$ Service providers often differ with respect to their goals and their range of service provision, thereby developing their own, often unique, approach to bereavement care. Although such services should, at least to some extent, reflect the nature and needs of the communities for whom they are developed, it is crucial that each service can also show its effectiveness for the population, which it serves. ${ }^{19}$ The current study findings are encouraging in that they suggest that the local service is performing well in terms of providing a range of service options that, according to client views, appear to be meeting most of the needs of its client base and is, in many respects, a good model of care. The results also provide a useful insight into a number of key ele- ments of bereavement support that seem to be working well together in this setting, as well as identifying lessons for improving the appropriate targeting and delivery of these services. This information is invaluable in the extent to which it will inform the development and optimal functioning of the local bereavement support service, as well as other similar palliative care bereavement services in Ireland and elsewhere. However, much further research in this area is needed.

\section{Acknowledgements}

The authors would like to thank the Irish Hospice Foundation (IHF) (Therese Brady Scholarship) who funded this study and all the staff and families at St Francis Hospice (SFH), Dublin wo agreed to participate in the study. We also acknowledge with thanks, the help and support of Ms Orla Keegan of the IHF and Dr Matthew Farrelly of the SFH.

\section{References}

1 Department of Health and Children. Report of the National Advisory Committee on palliative care; Dublin, 2003.

2 National Hospice and Palliative Care Organization. Standards of practice for hospice programs; Alexandria, VA, 2000.

3 London Bereavement Network. Bereavement care standards: bereavement network; London, 2001.

4 National Institute for Clinical Excellence. Services for families and carers: Improving supportive and palliative care for adults with cancer. The manual; London, 2004.

5 Parkes, CM. Guidelines for conducting ethical bereavement research. Death Stud 1995; 19: 171-181.

6 Wilkes, E. Characteristics of hospice bereavement services. J Cancer Care 1993; 2: 183-189.

7 McConville, U. Evaluation of the IPU ceremonies of remembrance at St Francis Hospice. Dublin: Mourning Rites; 2004.

8 Whyte, A. A critical appraisal of a voluntary hospice bereavement support service. Master Thesis, University College Dublin, 1990.

9 Gallagher, M, Tracey, A, Millar, R. Ex-clients' evaluation of bereavement counselling in a voluntary sector agency. Psychol Psychother: Theory Res Pract 2005; 78: 59-76.

10 Parkes, CM. Evaluation of a bereavement service. J Prev Psychiatry 1981; 1: 179-188.

11 Relf, M. The effectiveness of volunteer bereavement care. An evaluation of a palliative care bereavement service. $\mathrm{PhD}$ thesis, Goldsmith College, The University of London, 2000.

12 Vachon, M, Lydall, WAL, Rogers, J, Freedman, K, Freeman, SJG. A controlled study of self-help intervention for widows. Am J Psychiatry 1980; 137: 1380-1384.

13 Northern Area Health Board. Annual Report, 2004. 
14 Faschingbauer, TR, Zistook, S, Devaul, R. The texas revised inventory of grief. In: Zistook, S, (ed), Biopsychosocial aspects of bereavement. Washington DC: American Psychiatric Press; 1987. p. 111-124.

15 Plante, TG, Boccaccini, MT. The Santa Clara strength of religious faith questionnaire. Pastoral Psychol 1997; 45: 375-387.

16 Sherman, AC, Plante, TG, Simonton, S, Adams, DC, Burris, K, Harbison, C. Assessing religious faith in medical patients: cross-validation of the Santa Clara strength of religious faith questionnaire. Pastoral Psychol 1999; 2: 129-141.

17 Plante, TG, Vallaeys, CL, Sherman, AC, Wallston, KA. The development of a brief version of the Santa Clara strength of religious faith questionnaire. Pastoral Psychol 2001; 5: 359-368.
18 Field, D, Reid, D, Payne, S, Relf, M. Adult bereavement support services in five hospices in England. UK: The Health Foundation; 2005.

19 Thomas, J, Baker, D, Kassner, C. The Colorado bereavement services project: bereavement assessment and outcomes. In: Proceedings of the National Hospice and Palliative Care Organization; 2006.

20 Stroebe, MS, Stroebe, W. Who participates in bereavement research? Omega: J Death Dying 1989; 20: 1-29.

21 Sherman, AC, Plante, TG, Simonton, S, Adams, DC, Burris, K, Haribson, C. Assessing religious faith in medical patients: cross validation of the Santa Clara strength of religious faith questionnaire. Pastoral Psychol 1999; 2: 129-141. 


\section{Appendix}

\section{Section A}

Please answer the following questions by ticking the relevant box (es) or by filling in the relevant information in the space provided.

\section{(1) Bereavement Follow-up:}

1. Did you receive any contact from the Hospice in the first 6-8 weeks after your bereavement? Yes $\square \quad$ No $\square$

(a) If 'yes', please indicate the type of contact you received from the Hospice (tick all that apply)?

$$
\begin{aligned}
& \text { Visit } \\
& \text { Telephone } \\
& \text { Other contact (please specify) }
\end{aligned}
$$

(b) If you did receive contact from the hospice who contacted you? (Please tick all that apply)
A member of the nursing staff $\square$ Social worker(s) $\square$
Chaplain $\square$
Don't know/can't recall $\square$ Other (please specify)

$\begin{array}{ccc}\text { Unhelpful } & \begin{array}{c}\text { Neither unhelpful } \\ \text { nor helpful }\end{array} & \text { Helpful } \\ \square & \square & \square\end{array}$
(c) Please indicate how helpful you found this contact:

2. If you 'did not' receive any contact from the Hospice in the first 6-8 weeks after your bereavement, would you have liked a member of the hospice staff to have contacted you? $\quad$ Yes $\square$ No

\section{(2) Bereavement Information Night:}

Approximately 3 months after your friend/relative died, you received an invitation to an Information Night held at the hospice. It was a talk given by the social worker, called 'A Journey Through Bereavement'

3. Did you receive an invitation to the Information Night? $\quad$ Yes $\square \quad$ No $\square \quad$ Not sure/can't recall $\square$

4. Were you aware that the invitation allowed you to bring family/friends to the service? $\quad$ Yes $\square$

5. Did you feel you received sufficient notice of the Information Night? $\quad$ Yes $\square \quad$ No $\square \quad$ Not sure/can't recall $\square$

6. How did you feel on receiving the invitation to the Information Night?

Displeased $\begin{aligned} & \text { Neither Pleased Pleased } \\ & \text { Nor displeased }\end{aligned}$

\section{How did you feel on receiving the invitation to the Information Night?}

7. How did you find the timing of the Information Night after the death of your relative/friend?

8. If you felt the Information Night was 'too soon' or 'too late', when do you think would have been more appropriate (i.e. when after the death):

Within the first 2 weeks $\square \quad 2-4$ weeks $\square \quad 6$-8weeks $\square \quad$ after 8 weeks $\square$ Other (please specify) 
9. Did the time of the Information Night suit you (i.e. $7.30 \mathrm{pm}$, weekday)

Yes $\square \quad$ No $\square$

(a) If 'No', when would you have preferred the information night to be held:

At the weekend

Weekday morning

Weekday afternoon

Weekday early evening

Other (please specify)

10. How did you feel about the prospect of returning to the Hospice for the Information Night?

11. Would you have preferred the Information Night to be held at another venue?

Yes $\square \quad$ No $\square$

(a) If 'yes', where?

\section{PLEASE ANSWER THE FOLLOWING QUESTIONS IF YOU ATTENDED THE INFORMATION NIGHT. IF YO U DID NOT ATTEND PLEASE GO TO QUESTION 21.}

12. Approximately, how many relatives/friends attended the Information Night with you?

\section{Please rate the following}

13. The availability of car parking facilities

14. The venue for the service

15. The amount of staff present at the talk

16. The bereavement talk ('Journey through bereavement')

17. Overall, how satisfied were you with the information night.

\begin{tabular}{|l|l|l|l|l|}
\hline $\begin{array}{l}\text { Very } \\
\text { dissatisfied }\end{array}$ & $\begin{array}{l}\text { Quite } \\
\text { dissatisfied }\end{array}$ & $\begin{array}{l}\text { Neither satisfied } \\
\text { nor dissatisfied }\end{array}$ & $\begin{array}{l}\text { Quite } \\
\text { satisfied }\end{array}$ & $\begin{array}{l}\text { Very } \\
\text { satisfied }\end{array}$ \\
\hline & & & & \\
\hline & & & & \\
\hline & & & & \\
\hline & & & & \\
\hline & & & & \\
\hline
\end{tabular}

18. What information, if any, did you find most helpful or unhelpful? 
19. Did any of the staff whom you met during your relative/friend's contact with the hospice attend the Information Night?

(a) If 'No', who would you have liked to have seen at the Information Night?
Nursing staff $\square$ Social workers $\square$
Chaplain $\square$
Other (please specify)

20. Are there any ways in which you think the Bereavement Information Night could be improved?

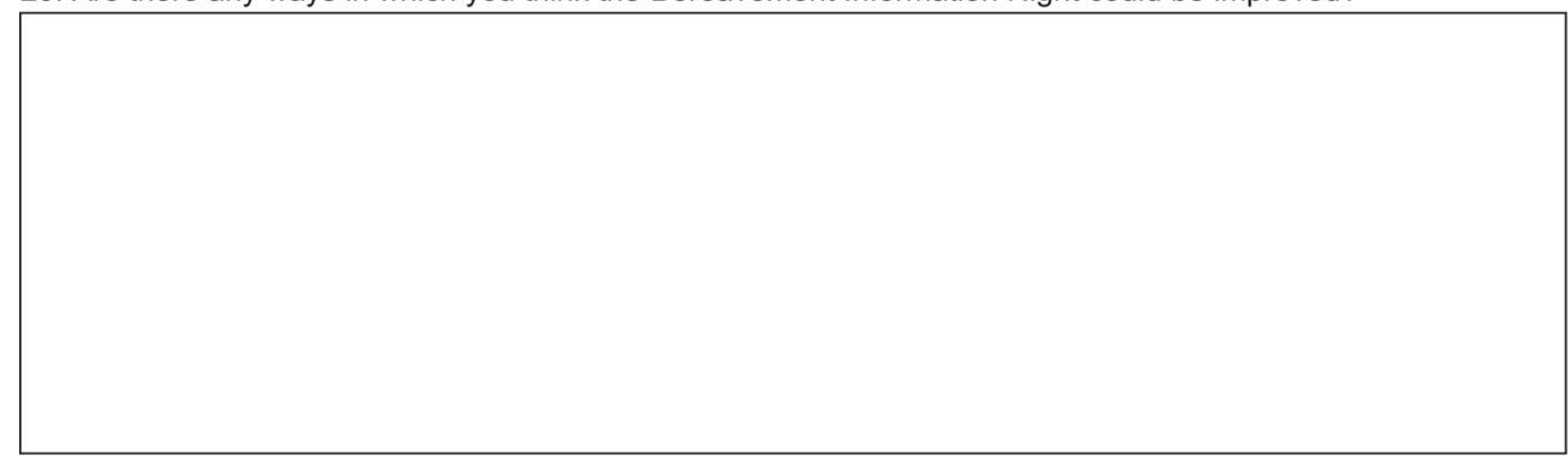

Please go to $\mathbf{Q} 22$.

\section{PLEASE ANSWER QUESTION 21 IF YOU DID NOT ATTEND THE INFORMATION NIGHT.}

21. Why did you choose not to attend the Bereavement Information Night (please tick as many as you wish)?

Felt it was too painful

Felt it was too soon after the death

Felt it was too long after the death

Did not want to return to the hospice

The time of the Information Night was inconvenient

Did not receive sufficient notice

Other (Please specify)

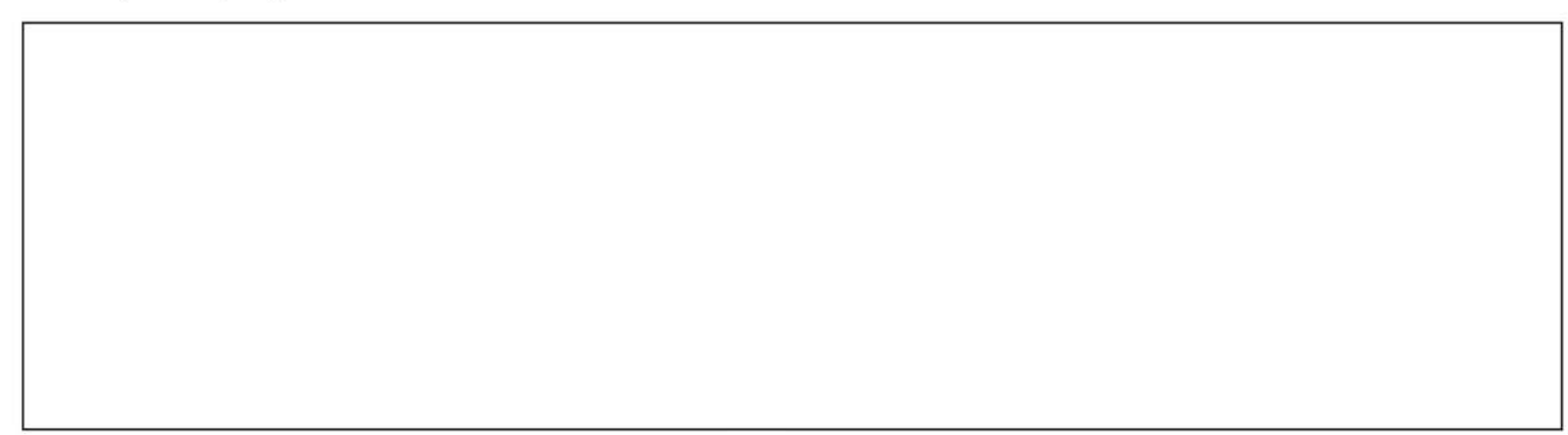

\section{(3) Volunteer Bereavement Support Service:}

The Bereavement Volunteer Support Service is an individual support service offered by Hospice bereavement volunteers.

22. Are you aware that the Hospice offers a Volunteer Bereavement Support Service (in which a volunteer provides one-to-one support)?

Yes $\square \quad$ No $\square$ 
23. If 'yes', where did you first hear about this service?

When visiting the Hospice during my relative/friends care A nurse informed me upon the death of my relative/friend At the memorial mass

At the Bereavement Information Night I phoned the hospice to enquire about services available Not sure/can't recall

Other (please specify)

24. Have you attended a individual session with a bereavement volunteer?

(a) If 'No', please state why.

25. If you have not used the Volunteer Bereavement Support Service, do you think you may use this service in the future?

(a) Please state why?

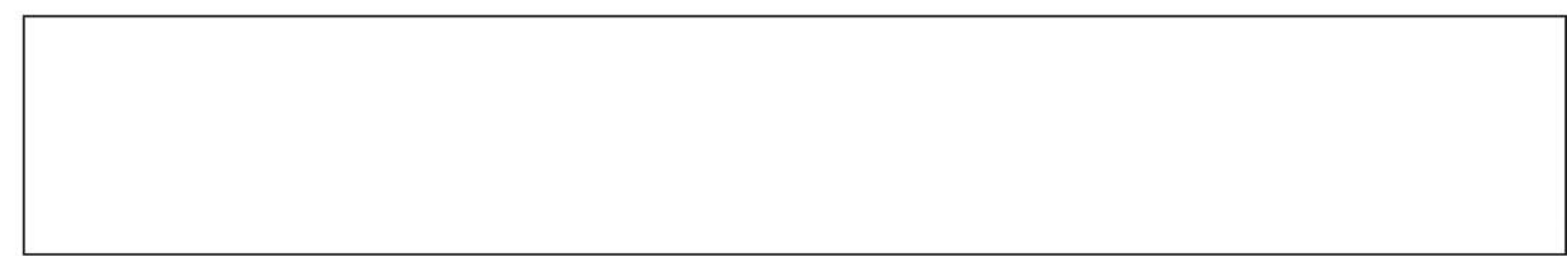

26. Would you have liked the option of attending a memorial mass at the Hospice a month after the death of your relative/friend?

Yes $\square \quad$ No $\square$

27. Have you used other support services (e.g counseling services, parish groups etc.) outside of St. Francis Hospice?

(a) If 'yes', what services have you used?

Yes $\square \quad$ No $\square$

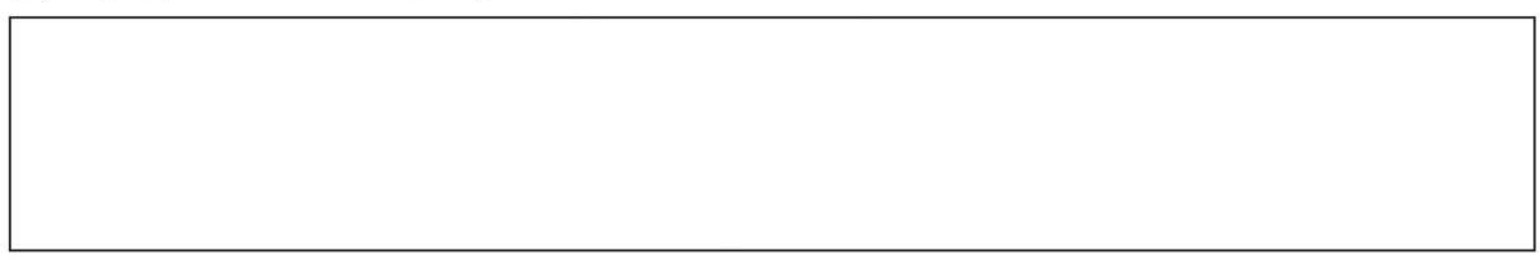

28. Did you attend:

The annual service of Remembrance held in Raheny church.

Yes $\square \quad$ No $\square$

The Christmas Tree Lighting ceremony held at St Francis Hospice.

Yes $\square \quad$ No $\square$

29. If you attended one or both of these services, please comment on what you thought of them? 


\section{Section B}

This section looks at how people may feel at the time of a bereavement and afterwards. It also includes some questions about your religious faith (if applicable) and support you received from family and friends. Please tick the appropriate box that you think best represents how you feel/felt.

\section{Part 1}

Think back to the time your relative/friend died and answer all of these items about your feelings and actions at that time by indicating whether each item is 'completely true', 'mostly true', 'both true and false', 'mostly false' or 'completely false' as it is applied to you after they died.

1. After my relative/friend died, I found it hard to get along with certain people.

2. I found it hard to work well after this person died.

3. After this person's death, I lost interest in my family, friends and outside activities.

4. I felt a need to do things that my relative/friend had wanted to do.

5. I was unusually irritable after this person died.

6 . I couldn't keep up with my normal activities for the first 3 months after this person died.....

7. I was angry that the person who died had left me.

8. I found it hard to sleep after this person died.

\begin{tabular}{|l|l|l|l|l|}
\hline $\begin{array}{l}\text { Completely } \\
\text { True }\end{array}$ & $\begin{array}{l}\text { Mostly } \\
\text { True }\end{array}$ & $\begin{array}{l}\text { True \& } \\
\text { False }\end{array}$ & $\begin{array}{l}\text { Mostly } \\
\text { False }\end{array}$ & $\begin{array}{l}\text { Completely } \\
\text { False }\end{array}$ \\
\hline & & & & \\
\hline & & & & \\
\hline & & & & \\
\hline & & & & \\
\hline & & & & \\
\hline & & & & \\
\hline & & & & \\
\hline & & & & \\
\hline
\end{tabular}

\section{Part 2}

Now please answer all of the following items by stating how you currently feel about the person's death. Please do not refer to Part 1.

1. I still want to cry when I think of the person who died........

2. I still get upset when I think of the person who died..........

3. I cannot accept this person is dead.

4. Sometimes I very much miss the person who died....

5. Even now, it is still painful to recall memories of the person who died.....

6. I am preoccupied with thoughts (often think) about the person who has died.....

7. I hide my tears when I think about the person who has died

8. No one will ever take the place in my life of the person who died.....

9. I can't avoid thinking about the person who has died...........

10. I feel it's unfair that this person has died....

11.Things and people around me still remind me of the person who has died.

12.I am unable to accept the death of the person who has died

13. At times, I feel the need to cry for the person who has died

\begin{tabular}{|l|l|l|l|l|}
\hline $\begin{array}{l}\text { Completely } \\
\text { True }\end{array}$ & $\begin{array}{l}\text { Mostly } \\
\text { True }\end{array}$ & $\begin{array}{l}\text { True \& } \\
\text { False }\end{array}$ & $\begin{array}{l}\text { Mostly } \\
\text { False }\end{array}$ & $\begin{array}{l}\text { Completely } \\
\text { False }\end{array}$ \\
\hline & & & & \\
\hline & & & & \\
\hline & & & & \\
\hline & & & & \\
\hline & & & & \\
\hline & & & & \\
\hline & & & & \\
\hline & & & & \\
\hline & & & & \\
\hline & & & & \\
\hline & & & & \\
\hline & & & & \\
\hline
\end{tabular}

\section{Part 3}

1. After my bereavement, I felt there was someone in my life I could talk to.

2. After my bereavement, I felt there was someone in my life who offered me practical support (e.g. helping with children, shopping etc.).

3. After my bereavement, I felt I had enough emotional support from my family and friends.

\begin{tabular}{|l|l|l|l|}
\hline $\begin{array}{l}\text { Strongly } \\
\text { disagree }\end{array}$ & Disagree & Agree & $\begin{array}{l}\text { Strongly } \\
\text { agree }\end{array}$ \\
\hline & & & \\
\hline & & & \\
& & & \\
\hline & & & \\
\hline
\end{tabular}




\section{Section C}

Please answer the following questions by ticking the relevant box(es) or by filling in the relevant information in the space provided.

1. How old are you?

2. Sex: Male $\square \quad$ Female $\square$

3. What level of education have you achieved?

$\begin{array}{llll}\text { Primary school } & \square & \text { Post leaving Certificate (PLC) } & \square \\ \text { Secondary school } & \square & \text { Apprenticeship } & \square \\ \text { University } & \text { Other (please specify) } \\ \text { Institute of technology } & \square & \end{array}$

4. What was the nature of your relationship to the person who died (e.g. my husband, parent etc.)?

$\begin{array}{lll}\text { Husband/wife/partner } & & \text { Relative } \\ \text { Parent } & \square & \text { Friend } \\ \text { Child } & \square & \text { Other (please specify) }\end{array}$

5. When did your relative/friend die? month _ year

6. How old was your relative/friend when he/she died?

7. Were you the main carer for your relative/friend?

Yes $\square \quad$ No $\square$

8. Did your relative/friend die at: The hospice $\square$ Home $\square \quad$ Hospital $\square$ Other (Please specify)

9. What Hospice service(s) did your relative/friend attend (please tick all that apply)?

Home care $\square \quad$ Day care $\square \quad$ Inpatient unit $\square \quad$ Did not attend any of the services $\square$

10. How long did your relative/friend attend the Hospice service(s)?

11. Were you present when your relative/friend died?

(a) I f 'No', would you have liked to have been there?

Yes $\square \quad$ No $\square$

Yes $\square \quad$ No $\square$

12. Do you feel your relative/friend's death was:

expected $\square$ unexpected $\square$

13. Do you now live: Alone $\square \quad$ With family $\square$

Other (please specify)

14. Do you have any dependants?

Yes $\square \quad$ No $\square$

(a) If 'yes', who? Parent(s) $\square \quad$ Child/children $\square \quad$ Other (Please specify)

15. Has there been another bereavement in your family since this one?

(a) If 'yes', who?

\begin{tabular}{|c|c|c|}
\hline \multicolumn{2}{|c|}{ Husband/wife/partner $\square$} & \multirow{2}{*}{$\begin{array}{l}\text { Relative } \\
\text { Friend }\end{array}$} \\
\hline Parent & 口 & \\
\hline Child & $\square$ & Other (please specify) \\
\hline
\end{tabular}

16. Did you have any other relative/friends who were cared for by the Hospice team?

Yes

No $\square$

(a) If 'yes', how many? 
Reproduced with permission of the copyright owner. Further reproduction prohibited without permission. 